\title{
PRODUÇÃO DE DISCURSOS SOBRE INCLUSÃO: UM ESTUDO DOS ANAIS DA ANPEd (2011- 2016)
}

\author{
LÖBLER. G. N.1; SANTOS, T. M.2; HILLESHEIM, B. ${ }^{3}$. \\ PALAVRAS CHAVE: Inclusão. Discurso. Educação.
}

\begin{abstract}
RESUMO
Este artigo compreende a inclusão inscrita numa determinada ordem discursiva, que a estabelece como um imperativo deste tempo. Para investigar os discursos sobre inclusão no âmbito da pesquisa acadêmica na Educação, elegeu-se como materialidade de pesquisa os resumos dos trabalhos publicados nas Reuniões Nacionais e Regionais Sul da ANPEd, entre os anos de 2011 e 2016. A análise voltou-se para os títulos, resumos e palavras-chave de 64 trabalhos das Reuniões Nacionais, concentrados nos grupos Educação Especial, Educação e Relações Étnico-Raciais e Educação Fundamental. Os resultados apontam que os trabalhos colocam a escola como um espaço privilegiado para a inclusão, bem como a ideia da inclusão como um direito. Ainda, há uma preocupação na análise e proposição de um conjunto de ações que deve ser operacionalizado para a efetivação da inclusão. Observa-se também a inclusão em constante relação com a exclusão, sendo colocada ora como oposta, ora como sinalizadora de que a inclusão é falha ou insuficiente, ora como complementar à inclusão. Por fim, considera-se importante realizar análises sobre quais práticas são produzidas pelos diferentes discursos, buscando problematizar o que está naturalizado e compreender como os sujeitos tornam-se o que são.
\end{abstract}

\section{PRODUCTION OF DISCOURSE ABOUT INCLUSION: A STUDY OF THE ANNALS OF ANPED (2011-2016)}

KEYWORDS: Inclusion. Discourse. Education.

\begin{abstract}
This article understands inclusion as being embedded within a certain order of discourse, which establishes it as an imperative of this time. In order to investigate the discourses about inclusion in the context of academic research in the field of education, this study utilized papers published in the National and South Regional ANPEd Meetings, between the years of 2011 and 2016, as research materials. The analysis looked at the titles, abstracts and keywords of 64 papers from the national meetings under the following categories: Special Education, Education and Ethno-racial Relations and Primary Education. The results show that the papers regarded school as a privileged space for inclusion, and affirmed the idea of inclusion as a right. Furthermore, there is a concern that drives the analysis and proposition of a number of actions that must be carried out in order to effect inclusion. It was also noted that inclusion is constantly linked to exclusion, which is sometimes regarded as its opposite, while at other times it is considered as an indicator that inclusion is flawed or insufficient, and, finally, as complementary to inclusion. Lastly, it is considered important to perform analyses on what practices are produced by different discourses, seeking to problematize what is naturalized and comprehend how subjects become what they are.
\end{abstract}

\footnotetext{
${ }^{1}$ Acadêmica do curso de Psicologia na Universidade de Santa Cruz do Sul. Bolsista de Iniciação Científica - CNPq.

2 Graduada em Psicologia pela Universidade de Santa Cruz do Sul.

${ }^{3}$ Doutora em Psicologia (PUCRS). Docente do Departamento de Psicologia e do Programa de Pós Graduação em Educação da Universidade de Santa Cruz do Sul.
} 


\section{INTRODUÇÃO}

A pesquisa Inclusão, diferença e políticas públicas: uma cartografia, da qual se origina esta escrita, investiga o modo como se constrói e circula a discursividade sobre a inclusão em diferentes campos na contemporaneidade. Assim, atenta-se para o fato de como os discursos acerca da temática são construídos, (re)produzidos e incitados em diferentes regimes de saber e mediante específicos exercícios de poder, a partir de condições específicas de aparição, crescimento e variação.

Dessa maneira, neste texto, tem-se como fundamento que os discursos não são apenas conjunto de signos, "uma estreita superfície de contato, ou de confronto, entre uma realidade e uma língua" (FOUCAULT, 2004. p. 54), mas "práticas que formam sistematicamente os objetos de que falam" (p. 55). Como efeito, tratase de pensar a produção de discurso em sua positividade, uma vez que falar não significa apenas expressar uma ideia, traduzir algo ou ainda utilizar-se das estruturas da língua, mas, sobretudo, "fazer alguma coisa" (p. 234). Além disso, para o autor, "não se pode falar de qualquer coisa em qualquer época" (p. 50), sendo que para que algo possa ser dito são necessárias determinadas condições de possibilidade, relacionadas a relações de poder específicas que fazem aparecer o objeto do qual se fala.

Nessa direção, no âmbito da presente investigação, é importante considerar não somente o fato de que se fala tanto sobre a inclusão na atualidade, mas igualmente quem as fala, de quais lugares se fala, a partir de que pressupostos, quais as instituições que incitam a fazê-lo, entre outros, visando compreender, como nos propõe Foucault (1985), sob quais formas e por quais meios se consegue agir sobre as condutas dos indivíduos. Portanto, como sublinha Fischer (2012), o discurso é tomado aqui como uma prática social, produzindo-se sempre mediante um complexo feixe de relações de poder. Mais do que simples referência a 'coisas', o discurso apresenta uma regularidade que lhe é intrínseca, a qual se impõe aos sujeitos falantes, os quais são inscritos em um certo campo discursivo.

Desde o final do século passado, de acordo com Veiga-Neto e Lopes (2011), a inclusão tem tido maior alcance nas agendas políticas internacionais e nacionais, nas legislações, na mídia e no campo da produção de conhecimento. Para os autores, diante dos diversos sentidos atribuídos ao termo inclusão, "é recorrente o caráter disciplinar e de militância” (p. 126) que a produz como um imperativo da contemporaneidade: é preciso/dever/correto incluir. Ou seja, a inclusão é vista como um princípio natural, moral e, portanto, inquestionável. Ao realizar tal problematização, os autores deixam claro que não se trata de julgar a inclusão como boa ou ruim, mas de reconhecer que os discursos sobre a inclusão estruturam novas compreensões e práticas e que, ao mesmo tempo, são produzidos por elas, fazendo operar uma determinada forma de sociedade.

Thoma e Kraemer (2017), ao discutirem a inclusão como um imperativo, a entendem como "uma estratégia de controle e regulação dos sujeitos, como uma forma de governo das diferenças, que opera sobre a conduta de todos e de cada um de nós" (s.p.). Para isso, o imperativo da inclusão articula procedimentos, cálculos e saberes com o intuito de condução da vida da população. Deve-se considerar, assim, que ao fazer funcionar a ideia de inclusão, busca-se ainda minimizar os riscos que possam ser ocasionados pela exclusão.

Nessa perspectiva, Hillesheim (2013), ao analisar as políticas públicas brasileiras, aponta a disseminação de slogans como "Luz para todos", “Educação para todos" e "Saúde para todos", entre outros. Tal profusão pode ser visualizada nos mais variados espaços: jornais, revistas, programas de televisão, campanhas nas ruas, redes sociais, meio acadêmico etc. Dito isso, a inclusão é tida como uma prática social recente que, 
com seu caráter imperativo, opera nos mais variados espaços da sociedade: todos devem ter acesso à luz, educação e saúde, todos devem estar incluídos, sendo que a ninguém é permitido ficar de fora.

Dessa maneira, pode-se entender essa incitação à inclusão a partir de uma racionalidade neoliberal, na qual:

\begin{abstract}
"As políticas de inclusão representam uma forma de garantir aqueles que uma vez excluídos da governamentalidade estatal adentrem a esfera pública ou a vida política e, especialmente, ao jogo concorrencial do mercado, oferecendo uma série de dispositivos que asseguram ao povo integrar as regras desse jogo e às normas jurídicas, econômicas e políticas do que se denomina de uma face formal e contratual de cidadania (PAGNI, 2019, p. 4)".
\end{abstract}

Michel Foucault (1998), ao escrever sobre a noção de jogos de verdade, afirma que "o discurso está na ordem das leis" (p. 07), isto é, não é possível falar de qualquer coisa ou dizer tudo, uma vez que é preciso obedecer a um determinado número de procedimentos, os quais controlam, delimitam, classificam e organizam a sua produção. Em outras palavras, em cada tempo, sob determinadas regras, determinados discursos assumem o estatuto do verdadeiro ou falso. A partir disso, pode-se entender que todos esses ditos sobre a inclusão que se multiplicam na contemporaneidade inscrevem-se numa determinada ordem discursiva que seleciona e legitima aquilo que pode ser dito.

Desse modo, o presente artigo volta-se para a investigação dos discursos sobre a inclusão (re)produzidos no âmbito da pesquisa acadêmica, mais especificamente na área da Educação. Para tanto, elegeu-se como materialidade de pesquisa os resumos dos trabalhos publicados nas Reuniões Nacionais e Regionais Sul da ANPEd (Associação Nacional de Pós-Graduação e Pesquisa em Educação), entre os anos de 2011 e 2016.

\title{
2 A INCLUSÃO COMO PRÁTICA SOCIAL
}

De acordo com Veiga-Neto e Lopes (2011), somente a partir do segundo mandato de Fernando Henrique Cardoso (FHC), de 1999 a 2002, que a noção de inclusão expandiu-se, ganhando maiores proporções do que a antiga visão "reducionista e primária" (p. 121) de que a escola seria capaz de solucionar a maior parte das problemáticas sociais e garantir a participação de todos em uma sociedade mais justa e igualitária. Se, conforme os autores, inicialmente a inclusão estava associada apenas às pessoas com deficiência no contexto escolar, com FHC ela passa a abranger inúmeras outras práticas, direcionadas para diferentes sujeitos, considerados de algum modo vítimas de discriminação e exclusão. Com os governos do presidente Luís Inácio Lula da Silva, de 2003 a 2010, e da presidente Dilma Roussef, de 2011 a 2016, as políticas de inclusão não só são mantidas, mas ampliadas, sustentando o discurso de que todos devem ser incluídos e todos devem incluir.

Especificamente no que tange à inclusão escolar dos alunos com deficiência, Thoma e Kraemer (2017) colocam que, a partir da década de 1990, o Brasil busca responder aos compromissos assumidos com a Organização das Nações Unidas (ONU) no sentido de uma educação inclusiva. Documentos internacionais, tais como a Conferência Mundial de Educação para Todos (em 1990, em Jomtien, na Tailândia) e a Conferência Mundial de Educação Especial (em 1994, em Salamanca, na Espanha), marcavam o compromisso dos países com a inclusão. Além disso, a inclusão também surgia como uma possibilidade de enfrentamento de problemas educacionais brasileiros, visto que o Brasil se encontrava entre os países com maior taxa de analfabetismo do mundo. Com esse objetivo, o país firmou parcerias com a UNESCO, a UNICEF, o Banco Mundial, o Programa das Nações Unidas para o Desenvolvimento (PNUD), o que resultou numa ampliação significativa de políticas educacionais voltadas para a população com deficiência. 
Para as autoras citadas acima, pode-se, portanto, afirmar que a década de 1990 se caracteriza por políticas sociais de inclusão e uma ampla reforma educacional, orientada por um consenso em torno da universalização de acesso. Desse modo, o governo Fernando Henrique Cardoso formulou diferentes ações que envolviam questões relativas à raça, étnica, deficiência, entre outras, no sentido de respeito à diferença, bem como buscando agir sobre questões de ordem estrutural e instrumental. Tais movimentos fazem que, no Brasil, haja, nesse período, um deslocamento de uma ideia da integração escolar, que era o paradigma até então vigente, para processos de educação inclusiva.

Tendo em vista tal contextualização, é possível perceber que a inclusão não é algo que esteve sempre aí ou se apresentou sempre da mesma forma. Entretanto, como discutido anteriormente, a inclusão, como um imperativo atual, estrutura-se em um discurso e uma prática cada vez mais naturalizada, impedindo, em muitos momentos, problematizações, críticas e/ou questionamentos. Sobre isso, Veiga-Neto e Lopes (2011) versam sobre a importância de um constante olhar crítico sobre as práticas atuais, tendo em vista que

\footnotetext{
"A naturalização dos processos sociais funciona como uma espessa camada de concreto que sepulta, sob si, o caráter inventado de tais processos. Esquecendo-se de que foram inventados, de que dependeram de determinadas contingências históricas localizadas e datadas, esses processos sociais passam a ser considerados como necessários, imutáveis e, assim, imunes à crítica. Esse é o caso da inclusão escolar (p. 126)".
}

Além disso, para os autores, tal naturalização relaciona-se a uma concepção homogênea do mundo, onde as desigualdades e exclusões são entendidas como artificiais, ou seja, como contrárias a uma suposta ordem natural de igualdade. Diante disso, alertam para “[...] os usos alargados da palavra exclusão, quando ela é entendida como ‘o outro da inclusão’" (p. 122). Sobre a temática, Lopes (2007) discorre que o espaço ocupado pela inclusão na contemporaneidade equivale ao espaço produzido para a exclusão. Em outras palavras, inclusão e exclusão não estabelecem entre si uma relação de oposição, pois são concepções tão fundidas quanto os lados de uma mesma moeda: uma vez que se têm diferentes sujeitos a incluir, diversas são as práticas para que a inclusão trabalhe em prol de si mesma e não acabe por promover o seu outro lado. Nesse sentido,

\footnotetext{
"As instituições que garantem o acesso e o atendimento a todos são, por princípio, includentes, mesmo que, no decurso dos processos de comparação e classificação, elas venham a manter alguns desses "todos" (ou muitos deles...) em situação de exclusão. Isso significa que o mesmo espaço considerado de inclusão pode ser considerado um espaço de exclusão. Conclui-se assim que a igualdade de acesso não garante a inclusão e, na mesma medida, não afasta a sombra da exclusão (VEIGA-NETO; LOPES, 2007, p. 958)".
}

Nessa interdependência, os processos inclusivos permitem trazer para perto os ditos anormais, aqueles considerados estranhos, distantes da norma. Dessa maneira, a inclusão também faz com que essas pessoas sejam submetidos a práticas normalizadoras. Além disso, tal aproximação implica tanto em colocar todos sob os olhos - no sentido de monitorá-los - quanto em garantir que todos participem dos jogos de mercado:

"A inclusão pode ser vista como o primeiro passo numa operação de ordenamento, pois é preciso a aproximação com o outro, para que se dê um primeiro (re)conhecimento, para que se estabeleça algum saber, por menor que seja, acerca desse outro. Detectada alguma diferenç, se estabelece um estranhamento, seguido de uma oposição por dicotomia: o mesmo não se identifica com o outro, que agora é um estranho. (...) se o normal depende do anormal para a sua própria satisfação, tranquilidade e singularidade, o anormal depende do normal para sua própria segurança e sobrevivência (VEIGA-NETO, 2001, p. 26-27)".

Para Veiga-Neto e Lopes (2011), a inclusão, na medida em que foi construída como um imperativo político, econômico, moral e humanitário, constituiu-se também enquanto uma estratégia de governamento, pautada na lógica neoliberal. Esta pressupõe a otimização de todos os espaços da estrutura social, a fim de garantir o desenvolvimento do capitalismo. A inclusão, desse modo, é compreendida como algo que potencializa 
a todos, no sentido da criação de outros modos de vida e da inserção nos diferentes espaços do capitalismo. A ideia de uma mudança de vida e de acesso ao mercado fomenta uma noção de corresponsabilização e de autorresponsabilização sobre as práticas inclusivas (LOPES et al., 2010).

Além disso, tendo em vista que, para Foucault (2004), os discursos são compreendidos como práticas que constituem os objetos de que falam, ou seja, as palavras "não são, como poderia se esperar, um puro e simples entrecruzamento de coisas e palavras" (p. 54), pode-se compreender que, na medida em que a inclusão legitima-se a partir de um estatuto de verdade, ela se afirma como tal, colocando-se como algo dado a priori, da ordem do universal. Seguindo essa lógica, Veiga-Neto e Lopes (2011) colocam que os discursos sobre inclusão e as práticas inclusivas mantém entre si uma relação de imanência, isto é, os discursos propiciam novas práticas inclusivas, ao mesmo tempo em que são produzidos por elas. 0 mesmo ocorre com os sujeitos quando são compreendidos como sujeitos incluídos: os mesmos passam a se entender e ser entendidos como tal. Nesse cenário, como assinalam Thoma e Kraemer (2017), ao mesmo tempo em que a inclusão é considerada um direito do cidadão, a sua racionalidade fomenta o próprio desenvolvimento econômico do Estado.

\section{A CONSTRUÇÃO DE CAMINHOS INVESTIGATIVOS}

O recorte da pesquisa aqui discutido voltou-se para a investigação dos discursos que são produzidos no campo da pesquisa acadêmica em Educação. Para isso, elegeu-se como materialidade de análise os resumos dos trabalhos publicados nas Reuniões Científicas Nacionais e Regionais Sul da ANPEd (Associação Nacional de Pós-Graduação e Pesquisa em Educação), entre os anos de 2011 e 2016. Entretanto, destaca-se que os resultados aqui discutidos e apresentados referem-se somente às Reuniões Nacionais, uma vez que a análise dos dados produzidos sobre as Reuniões Regionais Sul encontram-se em processo de finalização. No que se refere à periodicidade, as Reuniões Científicas Nacionais da ANPED, até o ano de 2013, eram anuais, sendo que, a partir dessa data, tornaram-se bienais. Portanto, as Reuniões analisadas aqui referem-se aos anos de 2011, 2012, 2013 e 2015.

0 primeiro passo para a produção de dados foi a seleção dos resumos dos trabalhos publicados nas Reuniões Científicas Nacionais da ANPEd, entre 2011 e 2016, que contemplavam no título, no resumo ou nas palavras-chave, o termo "inclusão". Também foram selecionados os trabalhos que empregaram termos similares - como "inclusivo/inclusiva". Assinala-se que os resumos publicados nos referidos anais estão organizados de acordo com Grupos de Trabalho (GTs) definidos pela própria ANPEd. Todos os resumos que atendiam à busca, foram salvos em pastas eletrônicas e, além disso, foram registrados em documento de texto, ambos separados por ano e grupo de trabalho.

No período citado, foram publicados um total de 1646 trabalhos e, destes, 106 contemplavam termos relacionados à inclusão. Entretanto, os GTs que publicaram uma quantidade mais expressiva acerca do tema foram Educação Especial (47 publicações), Educação e Relações Étnico-Raciais (10 publicações) e Educação Fundamental (7 publicações), conforme mostra o Quadro 1. Assim, somando-se os grupos de trabalho que mais versaram sobre inclusão no período designado, obtém-se um total de 64 trabalhos, que representam 3,88\% do total de trabalhos publicados nesses anos. 
Quadro 1. Quantidade de trabalhos publicados relacionados à inclusão por GTs

\begin{tabular}{|c|c|c|c|c|c|c|c|}
\hline GT & 2011 & 2012 & 2013 & 2015 & $\begin{array}{lr}\% & \text { em } \\
\text { relação } & \text { ao } \\
\text { total } & \text { de } \\
\text { trabalhos } & \\
\text { publicados }\end{array}$ & $\begin{array}{lr}\% & \text { em } \\
\text { relação } & \text { ao } \\
\text { total } & \text { de } \\
\text { trabalhos } & \\
\text { que } & \\
\text { contemplam } \\
\text { o termo }\end{array}$ & TOTAL \\
\hline $\begin{array}{l}15 \text { - } \\
\text { Educação } \\
\text { Especial }\end{array}$ & 14 & 8 & 10 & 15 & $2,85 \%$ & $44,33 \%$ & 47 \\
\hline $\begin{array}{l}21 \text { - } \\
\text { Educação e } \\
\text { Relações } \\
\text { Étnico- } \\
\text { Raciais }\end{array}$ & 3 & 1 & 4 & 2 & $0,60 \%$ & $9,4 \%$ & 10 \\
\hline $\begin{array}{l}13 \text { - } \\
\text { Educação } \\
\text { Fundamental }\end{array}$ & 1 & 3 & 0 & 3 & $0,42 \%$ & $6,60 \%$ & 7 \\
\hline \multicolumn{7}{|c|}{ TOTAL ABSOLUTO } & 64 \\
\hline & OTAL (9) & $\overline{E L A C A}$ & ÚMERC & $D E T R$ & S PUBLICA & & $3,88 \%$ \\
\hline
\end{tabular}

Em um segundo momento, para dar conta da análise dos discursos produzidos pela pesquisa acadêmica em Educação, esta foi dividida em três diferentes eixos. 0 primeiro, "sentidos da inclusão", investiga quais termos encontram-se atrelados à noção de inclusão e que podem se aproximar ou se equivaler ao termo. Destaca-se que alguns trabalhos trazem um sentido distinto daquele que busca esta pesquisa. Por isso, tais resumos, a exemplo de Embates entre o tradicional e o moderno: a matéria de aritmética na reforma Orestes Guimarães, foram selecionados no primeiro momento da pesquisa, porém foram descartados para análise, já que o sentido do termo não se aproxima daquele aqui estudado, isto é, o termo inclusão nesses trabalhos não se inscrevem naquilo que denominou-se aqui como discurso da inclusão. No segundo eixo, "agentes da inclusão", busca-se conhecer quem são os sujeitos e/ou instituições convidados a incluir. Como terceiro e último eixo, procura-se responder à questão "quem deve ser incluído?". A partir desses três eixos, o conteúdo dos trabalhos foi sistematizado em tabelas, também organizadas por ano e grupo de trabalho aos quais se referem.

Considerando essa sistematização, realizou-se a discussão desses dados, tendo como principal questão: “como a inclusão é enunciada no campo da Educação?”, detendo-se, na discussão aqui apresentada, apenas no primeiro eixo de análise, visto que se trata do principal operador da pesquisa. Nessa direção, são apresentados, a seguir, os principais achados dessa investigação.

\section{RESULTADOS}

Para fins da discussão aqui proposta, centrou-se a análise nos sentidos que a inclusão adquire nos diferentes artigos. Para isso, os dados foram compreendidos não a partir de uma análise quantitativa, a qual os consideraria sob a ótica das quantidades e frequências de sua ocorrência ${ }^{1}$, mas especialmente pelo que está sendo produzido pelo discurso da inclusão. Ao fazer isso, não se trata de apontar a configuração interna de tal

\footnotetext{
${ }_{1}$ Para uma maior discussão sobre esse aspecto, sugere-se a leitura do artigo intitulado A produção de sentidos sobre a inclusão na pesquisa
} acadêmica em psicologia e educação, de Granata et al (2018). 
discurso ou explicitar suas possíveis contradições. Mas, como indica Foucault (2004), intenta-se descrever os acontecimentos discursivos, tomando-os como "horizonte para a busca das unidades que daí se formam" (p. 30), considerando que se trata de um conjunto sempre finito, o qual é construído a partir de regras estritas sobre o que pode e deve ser dito em determinado contexto histórico. Parte-se também da compreensão de que, como pontua Fischer (2012), os enunciados são necessariamente dispersos, sendo que o trabalho do pesquisador consiste em "constituir unidades a partir dessa dispersão, mostrar como determinados enunciados aparecem e como se distribuem no interior de um certo conjunto, sabendo, em primeiro lugar, que a unidade não é dada pelo objeto de análise (p. 81).

Ao olhar para os diferentes trabalhos acadêmicos analisados, podem ser circunscritos alguns marcadores, dentre os quais, com vistas aos objetivos do presente texto, destacam-se: a escola como espaço privilegiado para inclusão; a noção de inclusão como direito; a inclusão como um conjunto de ações que devem ser operacionalizadas; e a inclusão em relação à exclusão. Ao propor tais marcadores, alertados por Fischer (2012), salienta-se que o esforço de constituir unidades não significa uma simplificação, uma busca de organizar aquilo que se encontra desorganizado: ao contrário, trata-se justamente de evidenciar que o discurso é um lugar de multiplicação. Nessa direção, os marcadores aqui propostos não se pretendem totalizantes, mas mostrar sua complexidade: assim, pode-se dizer que os marcadores se mesclam, compondo diferentes aspectos da inclusão, ora complementares, ora antagônicos, num quadro sempre por completar.

No que se refere ao primeiro ponto, a escola como espaço privilegiado para inclusão, é preciso lembrar que a produção de dados deu-se em trabalhos acadêmicos do campo da Educação, sendo esperado tal resultado. Além disso, historicamente, as lutas pela inclusão estão estreitamente relacionadas com a questão da deficiência e com preceitos educacionais inclusivos (MACEDO et al., 2014). Desse modo, Thoma e Kraemer (2017) identificam três momentos da inclusão das pessoas com deficiência no Brasil: 1) a inclusão como reclusão; 2) a inclusão como integração e 3) a inclusão como um direito e imperativo de Estado. Com a ressalva de que tais momentos não são lineares e tampouco podem ser facilmente delimitados, pode-se pensar que há um deslocamento de ênfases em diferentes épocas, mediante determinados regimes de verdades que legitimam como deve se compreender e operacionalizar a educação das pessoas com deficiência.

Doebber e Traversini (2011), ao investigar sobre ações afirmativas, apontam sua expansão em diferentes partes do mundo. Dizem as autoras que, nos últimos anos, é possível identificar um incremento de políticas públicas voltadas a grupos minoritários, tais como mulheres, pessoas com deficiência, homossexuais, população negra, população indígena, etc., com o objetivo de garantia de direitos calcados nos princípios de igualdade e equidade. Nesse sentido, uma série de documentos nacionais e internacionais (entre os quais, destacam-se a Declaração de Jomtien, em 1990, a Declaração de Salamanca, em 1994, a Constituição Federal de 1988 , o Estatuto da Criança e do Adolescente, em 1990, a Lei de Diretrizes e Bases, em 1996, o Plano Nacional de Educação, em 2001 e a Política Nacional de Educação Especial na Perspectiva da Educação Inclusiva, em 2008) foram dando à inclusão os contornos pelas quais hoje ela é compreendida não dentro de um modelo de institucionalização ou de serviços, mas numa perspectiva de educação inclusiva, na qual há um deslocamento da própria área da Educação Especial, que passa a ser colocada como transversal e complementar ao ensino regular (MACEDO et al., 2014; PAGNI, 2019). Assim, de acordo com Pagni (2019), com o crescimento das matrículas de alunos com deficiência na rede pública e privada, em 2008, a Política Nacional de Educação Especial na Perspectiva da Educação Inclusiva buscou garantir não somente a ampliação das matrículas, mas, sobretudo o acesso e a permanência dos alunos com deficiências nas escolas, "proporcionando-lhes condições 
de igualdade no acesso aos saberes e práticas em circulação, de acessibilidade aos meios para deles se apropriar e de dignidade nas relações de sociabilidade produzidas nessa instituição" (p. 2).

Desse modo, também se fazem presentes um conjunto de trabalhos que se voltam para a ideia da inclusão como um direito, mediante o uso de variados termos, tais como: direito à educação, direito de todos, princípios inclusivos, perspectiva inclusiva, participação, inserção, direitos humanos, entre outros. Guareschi, Lara e Adegas (2010) pontuam que as políticas públicas constituem-se como um modo de intervenção do Estado Moderno, que pretende maximizar a vida mediante a garantia de determinadas condições consideradas importantes para a potencialização de forças da população (saúde, educação, saneamento etc.). Para tanto, o Estado Moderno construiu

"A figura de um sujeito dotado de direitos civis, políticos, sociais, econômicos e culturais a partir de diferentes práticas estatais e não-estatais de intervenção nos fenômenos relativos à vida da população. É um processo que aproxima diretamente Estado moderno, Políticas Públicas e Sujeito de Direitos na construção do elemento subjetivo das políticas públicas (p. 338)".

Entretanto, a partir da discussão realizada por Michel Foucault, os autores argumentam que, ao lado do sujeito de direitos coexistem a figura que foi denominada pelo filósofo francês de homo aeconomicus, o qual emerge não de uma relação contratual com o Estado (no qual, mediante um contrato social, os sujeitos, no intuito de resguardar a alguns de seus interesses, renunciam a outros), mas de uma forma-mercado, na qual os sujeitos estabelecem entre si uma relação concorrencial, cada um agindo de acordo com seu próprio interesse, gerando um movimento generalizado de interesses coletivos.

Tal coexistência, entre o sujeito de direitos e o homo aeconomicus traz, no âmbito das políticas públicas, uma série de tensionamentos:

\begin{abstract}
"Ao mesmo tempo em que o sistema jurídico funda o sujeito de direitos, sujeito por excelência das políticas públicas, o mercado, a partir da perspectiva neoliberal, funda o homo œconomicus, sujeito do interesse, do jogo de interesses que acontece em função da não ação direta do Estado na economia. A questão que se coloca nessa configuração forjada pelo neoliberalismo norte-americano consiste em saber como investir na população através das políticas públicas em um espaço de soberania povoado por sujeitos econômicos, sendo que a teoria jurídica (do sujeito de direitos) não se ajusta à mecânica característica do homo œconomicus (GUARESCHI; LARA; ADEGAS, 2010, p. 338)".
\end{abstract}

Pode-se pensar, a partir dessas reflexões, que a emergência e difusão da inclusão se insere em um jogo complexo: por um lado, se pauta em discursos de direitos e é impulsionada pelas lutas dos movimentos sociais, assim como pelos compromissos internacionais firmados pelo Brasil; por outro, na medida em que é regida por uma racionalidade neoliberal, busca-se transformar os sujeitos da inclusão em partícipes dos jogos de mercados, tornando-os produtivos (THOMA; KRAEMER, 2017).

Outro ponto a considerar é que, em algumas situações, as políticas de inclusão acabam por circunscrever as pessoas com deficiência em um lugar compensatório. Isso porque, como alerta Pagni (2019), sem a problematização das relações de poder implicadas nesse processo, as pessoas com deficiência acabam por serem vistas como jogadores em desvantagem, os quais devem se filiar à racionalidade neoliberal e participar do jogo concorrencial, sem considerar a potencialidade de suas existências.

Por outro lado, também é possível entender que, uma vez que a inclusão passa a ser enunciada como um direito (e, no seu contraponto, também como um dever, visto que todos - professores, comunidade escolar, Estado, sociedade em geral - precisam se colocar como agentes da inclusão), tal imperativo, como assinala Lopes e Morgenstern (2014, p. 184), "ao acessar e ao inventar novas práticas, bem como ao montar distintas estratégias inclusivas, enuncia uma mudança de vida para todos a partir da corresponsabilidade pelo outro e da 
autorresponsabilização de cada um consigo mesmo". Dessa maneira, como discutem as autoras citadas, constitui-se uma matriz de experiência, ou seja, a inclusão não apenas como uma estratégia para que todos possam participar do jogo econômico ou como criação de normativas de comportamentos e subjetividades inclusivas, mas também fazendo emergir arranjos de vida até então impensados. Ou seja, a partir do chamamento desses sujeitos a serem incluídos, sendo a inclusão produzida como um direito, esses corpos incluídos trazem, para a Educação, diferentes desafios, tensionando a relação entre sujeito de direitos e o homo aeconomicus: não somente corpos a serem normalizados e adaptados aos jogos do mercado, mas corpos que, ao não se enquadrarem nesses parâmetros, também forçam constantemente seus limites, obrigando a Educação a se reinventar. É nessa perspectiva que se pode também compreender o conjunto de trabalhos que têm por objetivo propor e operacionalizar práticas inclusivas, discutir a formação dos professores, apontar limitações de acesso etc.

Outro marcador analisado diz respeito ao entrelaçamento das noções de inclusão e exclusão: o termo exclusão aparece de variadas formas (exclusão, prática pedagógica excludente, evasão escolar, exclusão escolar, inexistência de políticas inclusivas, desfiliação social, perspectivas seletivas e excludentes ditadas pela sociedade, entre outras), sendo colocado ora como oposto à inclusão, ora como sinalizador de que a inclusão é falha ou insuficiente, ora como complementar à inclusão. De qualquer modo, como ressaltam Veiga-Neto e Lopes (2011), é possível perceber que a exclusão, muitas vezes, é percebida como natural, sendo que o seu uso por vezes está em consonância com uma lógica dicotômica que coloca inclusão e exclusão como opostas, e, em outros momentos, entende que há uma fusão entre esses polos. De qualquer maneira,

\footnotetext{
"Ao lado das noções de direitos humanos, democracia e cidadania, a inclusão é quase sempre assumida como um princípio dado, inquestionável, inatacável. Tal inquestionabilidade da inclusão está ligada ao entendimento de que o mundo é isotrópico, isso é, o mundo - natural ou social, pouco importa - é, por si mesmo e em si mesmo, um espaço igual e homogêneo para tudo o que nele existe, aí incluídos nós, os seres humanos (p. 127)".
}

Diante disso, argumenta-se que o uso do termo exclusão nos diferentes trabalhos está estreitamente relacionado à noção da inclusão como um direito. Na medida em que a exclusão (e, consequentemente, seu par dicotômico, a inclusão) não é problematizada a partir das relações de poder que produzem sujeitos in/excluídos em uma racionalidade governamental neoliberal, muitas vezes se têm como efeito a ideia de que a inclusão é algo que diz respeito ao indivíduo, o qual se encontra, por determinadas condições físicas ou sociais, em uma situação de desvantagem em relação aos outros. 0 risco de tal entendimento reside, como marcam Veiga-Neto e Lopes (2011), na construção de uma ideia generalizada de que incluir significaria a restauração de uma suposta ordem natural perdida.

\section{CONSIDERAÇÕES FINAIS}

Ao tomar como campo de análise e discussão a pesquisa acadêmica na área da Educação, os resultados indicam para uma proliferação discursiva da inclusão como um imperativo, entendendo-a como uma prática desejável, vantajosa e um ideal a ser alcançado, visto que se constitui como um direito. Nessa perspectiva, a escola é colocada como central para que a inclusão aconteça, sendo que são ofertadas uma série de práticas que visam à construção de uma sociedade mais inclusiva. Na esteira da naturalização da inclusão, a exclusão é evidenciada como algo a ser evitado, par dicotômico da inclusão. Percebe-se, portanto, a produção da inclusão 
como uma verdade, a qual produz um modo de entender o mundo e as relações que se estabelecem entre inclusão e exclusão, atingindo diferentes campos e esferas do cotidiano.

Considera-se que, no atual contexto do país, é particularmente importante realizar análises sobre quais práticas são produzidas pelos diferentes discursos, buscando, a partir disso, problematizar o que está naturalizado e compreender como os sujeitos tornam-se o que são. Nesse sentido, é preciso apontar, como faz Pagni (2019), que, se por um lado, vive-se, no país, um momento de refluxo nas políticas inclusivas, especialmente no que diz respeito a ações governamentais, por outro, evidencia-se que a lógica de governamentalidade neoliberal tem se reconfigurado na direção de amenizar as demandas por inclusão de diferentes grupos, tornando-os ainda mais expostos a estados de dominação e violência. Uma das consequências disso são as atuais defesas ao retorno das instituições asilares (manicômios, classes especiais), buscando-se uma saída da perspectiva inclusiva, tida como fracassada na contenção daquilo - e daquele - que é compreendido como ameaça, ingovernável e, que, portanto, deve ser contido a qualquer preço.

A partir disso, concorda-se com o autor acima citado de que, mais do que criticar as políticas de inclusão, "é preciso rever as estratégias dos campos de saberes e técnicas que legitimaram suas ações, inclusive, aqueles que se postulam no presente e visam dissolver a sua perspectiva inclusiva" (PAGNI, 2019, p. 14).

Considera-se relevante assinalar que a discussão aqui proposta compõe uma investigação maior, sendo necessário avançar nas análises e nas articulações entre os dados produzidos nos diferentes recortes da pesquisa. Entretanto, ao trazer algumas questões relativas ao modo como a inclusão está sendo produzida no campo da Educação, pode-se contribuir para a compreensão de como tais discursos produziram o presente e as relações com a diferença, constituindo todos como sujeitos in(ex)cluídos e in(ex)clusivos.

\section{REFERÊNCIAS}

DOEBBER, Marcela Barcelos; TRAVERSINI, Clarice Salete. Os processos de in/exclusão na universidade: uma análise sobre ingresso e permanência de estudantes cotistas negros nos cursos de engenharia da UFRGS. In: THOMA, Adriana; HILLESHEIM, Betina. (org.) Políticas de inclusão. Gerenciando riscos e governando as diferenças. Santa Cruz do Sul: EDUNISC, 2011. p. 261-284.

FISCHER, Rosa Maria Bueno. Trabalhar com Foucault. Arqueologia de uma paixão. Belo Horizonte: Autência, 2012.

FOUCAULT, Michel. A ordem do discurso. 4.ed. São Paulo: Edições Loyola, 1998.

História da sexualidade. A vontade de saber.7a ed. Rio de Janeiro: Edições Graal, 1985.

A arqueologia do saber. 7 ed. Rio de Janeiro: Forense Universitária, 2004.

GUARESCHI, N..; LARA, L. ADEGAS, M. Políticas públicas entre o sujeito de direitos e o homo œconomicus. Psico, Porto Alegre, v. 41, n. 3, p. 332-339. Disponível em: http://revistaseletronicas.pucrs.br/ojs/index.php/revistapsico/article/view/8163/5854. Acesso em: 10 mar. 2019.

HILLESHEIM, Betina. É preciso incluir! Políticas públicas e o imperativo da inclusão. In: CRUZ, L.; RODRIGUES, L.; GUARESCHI, Neuza. Interlocuções entre a Psicologia e a Política Nacional de Assistência Social. Santa Cruz do sul: EDUNISC, 2013. p. 2330. Disponível em:

https://repositorio.unisc.br/jspui/bitstream/11624/1827/1/Interlocu\%C3\%A7\%C3\%B

5es\%20entre\%20a\%20psicologia\%20e\%20a\%20pol\%C3\%ADtica\%20nacional\%20d

e\%20assist\%C3\%AAncia\%20social.pdf\#page=24. Acesso em: 16 jan. 2019. 
LOPES, Maura Corcini; MORGENSTERN, Juliane M. Inclusão como matriz de experiência.Pro-Posições, Campinas , n. 2, p. 177-193, ago. 2014. Disponível em http://www.scielo.br/scielo.php?script=sci_arttext\&pid=S0103$73072014000200010 \&$ Ing=en\&nrm=iso. Acesso em 15 mar. 2019

LOPES, Maura Corcini. Inclusão escolar: currículo, diferença e identidade. In: LOPES, M. C.; DAL'IGNA, M. C. In/exclusão nas tramas da escola. Canoas: Editora Ulbra, 2007. p. 11-33.

LOPES, M. et al. Inclusão e biopolítica. Cadernos IHU Ideias, São Leopoldo, ano 8, n. 144, 2010. Disponível em: http://www.ihu.unisinos.br/images/stories/cadernos/ideias/144cadernosihuideias.pdf . Acesso em: 16 jan. 2019.

MACEDO, M. et al. Histórico da inclusão escolar: uma discussão entre texto e contexto. Psicologia em estudo, Maringá, n. 2, p. 179-189, abr./jun. 2014. Disponível em http://www.scielo.br/scielo.php?script=sci_arttext\&pid=S1413-73722014000200002\&lng=en\&nrm=iso. Acesso em: 15 mar. 2019.

PAGNI, Pedro A. Dez anos da PNEEPEI: uma análise pela perspectiva da biopolítica. Educação \& Realidade, Porto Alegre, n. 1, p. 01-20. Disponível em: http://www.scielo.br/scielo.php?script=sci_arttext\&pid=S217562362019000100208\&lng=pt\&nrm=iso\&tIng=en. Acesso em: 15 mar. 2019.

THOMA, Adriana da Silva; KRAEMER, Graciele Marjana. A educação de pessoas com deficiência no Brasil. Políticas e práticas de governamento. Curitiba: Apris, 2017.

VEIGA-NETO, A. da; LOPES, M. C. Inclusão e governamentalidade. Educação \& Sociedade, Campinas, n. 100, p. 947-963, out. 2007. Disponível em: http://www.scielo.br/pdf/es/v28n100/a1528100.pdf. Acesso em: 16 jan. 2019.

Inclusão, exclusão, in/exclusão. Verve, São Paulo, v. 30, p. 121-135, 2011. Disponível em: https://revistas.pucsp.br/verve/article/view/14886/11118. Acesso em 15 fev. 2019.

VEIGA-NETO, Alfredo da. Incluir para saber. Saber para excluir. Pro-posições, v. 12, Campinas, n. 2-3, p. 22-31, 2001. Disponível em: https://periodicos.sbu.unicamp.br/ojs/index.php/proposic/article/viewFile/8643993/1 1442. Acesso em 16 jan. 2019 